\title{
The real swindle
}

\author{
MAX BOYKOFF
}

\section{Climate change must be reported more carefully to help distinguish convergent agreement from legitimately contentious issues.}

$\mathrm{n}$ the US Republican debate in Iowa on 12 December 2007, Carolyn Washburn of the daily broadsheet The Des Moines Register asked the question, "How many of you believe global climate change is a serious threat and caused by human activity?"

This line of questioning was seen as an advancement on the usual indifference; a January 2008 League of Conservation Voters study found that only three of 2,275 questions put to the candidates in both parties in 2007 mentioned global warming ${ }^{1}$.

Although it was a welcome shift, Washburn's question contained the crucial mistake of conflating two distinct questions into one: whether climate change is a 'serious threat' and whether humans contribute to it.

Whereas the latter aspect is one of clear scientific consensus, the former is a judgment call, worth legitimate debate and discussion. But by merging these issues into a single question, Washburn allowed candidates to skirt both issues with general responses: "I believe that global climate change is serious" (Rudy Giuliani), and "I think that climate change is real" (John McCain).

If this journalistic act is celebrated as a breakthrough, how far have we really come in communicating climate change to the public?

\section{THE CLIMATE GESTALT}

In recent decades, media coverage of climate change has increased substantially (Fig. 1). Disasters such as the 2005 hurricane season in the US, the 2006 droughts in Australia and the 2007 floods in the UK and India have each provided the 'hook' for a flurry of climate-related news stories. Events like the 2006 release of Al Gore's documentary An Inconvenient Truth and the 2007 UN Climate Change Conference in Bali have further added to the multitude of media reports.

Evidence suggests that coverage of some areas of climate change is improving. For instance, attribution of climate change to human activity has received accurate coverage recently in a number of sources,

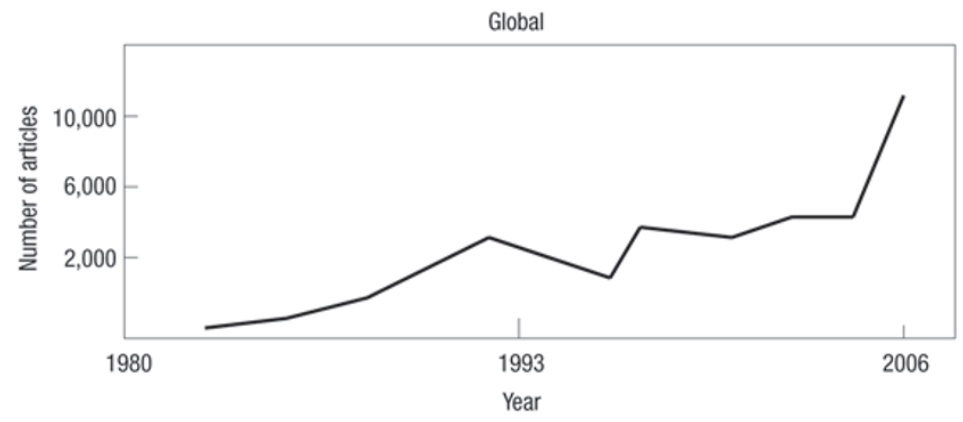

Figure 1 Trends in climate change coverage. Shown are the number of newspaper articles that contained the phrase 'climate change' or 'global warming' each year from 1980 to 2006, from the Lexis-Nexis and Proquest/ ABI Inform databases. This includes coverage in 41 of the most influential English-language newspapers, across 17 countries and on five continents.

including The Wall Street Journal, The Washington Post, USA Today, The Times (London), The New York Times, The Los Angeles Times, The Independent and The Guardian ${ }^{2}$. The role of the journalist is not that of a parrot; choices about how to represent various aspects of climate science and policy through the media depend on available information, interpretation and context ${ }^{3}$. Yet with the exception of excellent reporting by some journalists, such as Andrew Revkin of The New York Times, Seth Borenstein of The Associated Press and David Shukman of the $\mathrm{BBC}$, an overall trend of inadequate coverage by the mass media persists.

Many challenges exist across climate reporting, but the example from the Republican debate in Iowa highlights one of the most pressing: all too often, media reports conflate the vast and varied terrain of climate science and policy as a unified issue. This is very troubling. To the extent that mass media fuse all climate-related issues into a gestalt as 'the climate change debate', the public is poorly served. It contributes to continued illusory and counterproductive debates within the public and policy communities.

\section{CONFUSING THE ISSUES}

On the extreme end of the scale, conflation extends to deliberate manipulation, thus breeding confusion. The 2007 documentary The Great Global Warming Swindle combined many distinct issues into one 'great swindle' by misinterpreting research findings, editing interviewee comments and manipulating graphs to build a seemingly convincing argument that humans do not actually contribute to climate change.

The UK broadcast, watched by some 2.5 million viewers, provoked reactions from numerous climate scientists and policymakers, including prominent figures such as David Miliband, then the UK secretary of state for the environment, and Myles Allen of the University of Oxford. In the six weeks that followed, nearly 250 complaints were filed with the UK Office of Communications. Director Martin Durkin later acknowledged many of the problems and inaccuracies, but by that stage the seeds of public misunderstanding of the role of human activity in climate change had been sown through the inexact and hence misleading program. 
Media representations and convergence/divergence

of views in climate science and policy
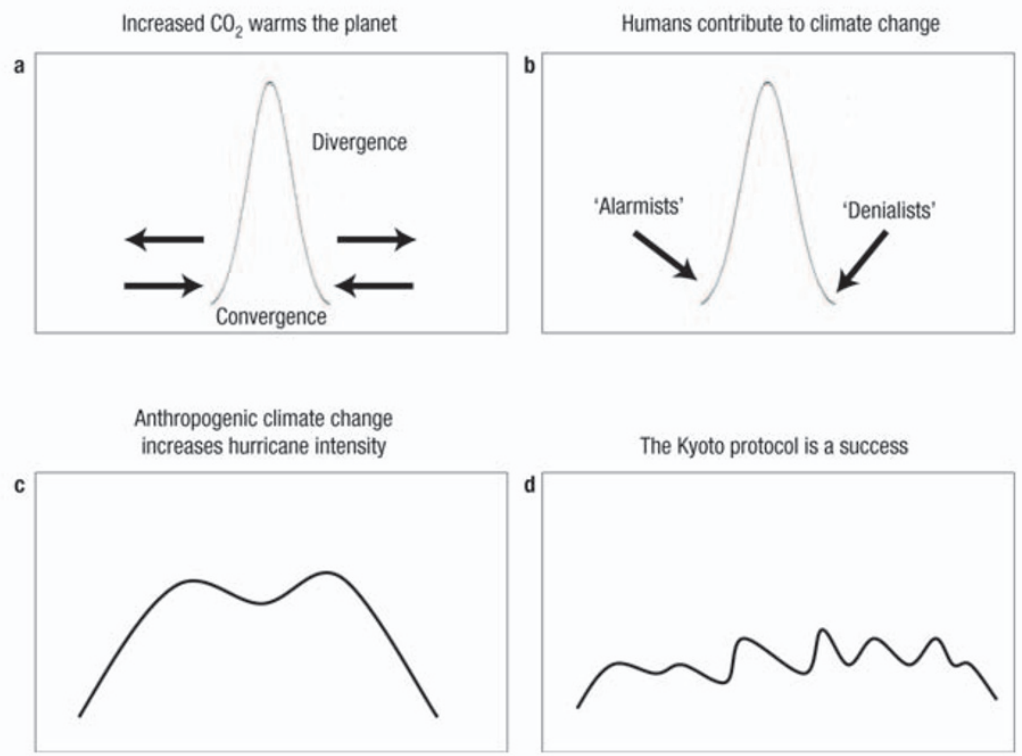

Figure 2 Patterns of agreement and disagreement on climate issues. Schematic adapted from comments by Andrew Revkin at the 2006 Society of Environmental Journalists meeting. The curves illustrate the relative strength of agreement or disagreement on selected statements about climate science and policy. Views converge strongly on some, such as the statement that 'increased C02 warms the planet' (a). They can also be bimodal, as seen in c, where two groups in the scientific community find links between hurricane intensity and climate change to be evident or absent, respectively.

Legitimate disagreement and dissent, however, have value in shaping understanding. All aspects of climate change should not be treated equally by the media; there are facets of climate change where agreement is strong, whereas for others contentious disagreement garners worthwhile debate and discussion (Fig. 2). For example, the statement 'humans contribute to climate change' meets with much consensus (Fig. 2b). On this topic, increased scientific understanding has contributed to greater convergence; divergence has come from those at either end of the spectrum, dubbed 'alarmists' and 'denialists' - the former believing that human contributions explain all climate changes, and the latter believing that they explain none. In contrast, the statement 'the Kyoto Protocol is a success' remains a subject worthy of ongoing discussion throughout the science, policy and public communities (Fig. 2d).

When journalists and editors do not effectively place the issues in the context of such views, public understanding suffers. As New York Times journalist Andy Revkin writes, "The media seem either to overplay a sense of imminent calamity or to ignore the issue altogether because it is not black and white or on a time scale that feels like news. This approach leaves society like a ship at anchor swinging cyclically with the tide and not going anywhere. What is lost in the swings of media coverage is a century of study and evidence...." Inadequate media translations of climate change have generated, as Revkin puts it, "probably more public confusion and cynicism about what is going on"4.

\section{COMPLEXITY IN CONTEXT}

Climate change is complex, which makes it a continually vexing problem for reporting, especially for a generalist audience. But in this high-stakes challenge, journalists and editors as well as scientists need to be intensely scrupulous. Media coverage should portray the contours of the varied aspects of climate change - from humans' role in it to whether it is 'serious' - because better reporting has crucial implications for furthering understanding and potential public engagement. Granted, news will not provide the answer to climate change, but it does help to address, analyze and discuss the issues. And although news coverage does not determine public engagement with an issue, it does influence its possibilities.

To this end, reporting must be more exacting. Despite pressures to churn out stories with greater frequency, journalists and editors must work to be more specific and clear as to what aspect of climate change - from physical science to impacts to policy action - is being covered, while also putting coverage more effectively into context. Journalists can begin with three concrete improvements: first, they can coordinate with editors to make headlines more consistent with the stories; second, they can more effectively label sources by their affiliation; and third, they can more frequently and consistently fact-check their reporting by consulting with appropriate experts. Greater contextualization within climate-science stories helps to ward off misdirected controversy ${ }^{5}$ and to sort marginalized views from counter-claims worthy of consideration.

The responsibility for clear communication on climate change rests not just with mass media. Scientists can play a pivotal role by engaging more consistently with journalists and editors to help them understand the nuances of climate science, as well as to better appreciate the pressures that media communities face in communicating climate change.

Moreover, scientists must recognize the increasing expectation that they interact with policymakers, media and the public. Organizations and initiatives such as the Aldo Leopold Leadership program foster these interactions, and scientists should get involved. Such shifts of focus have positive benefits in the short term - for example, improved reporting on one's research - as well as enhancing policy and public understanding of climate science in the long term.

More media coverage of climate change - even if fair and accurate coverage - is not a panacea. However, improved reporting with greater specificity and contextualization through the combined efforts of journalists, editors and scientists would help to more effectively engage the public, and would widen the spectrum of possibility for appropriate action.

Published online: 21 February 2008.

\section{doi:10.1038/climate.2008.14}

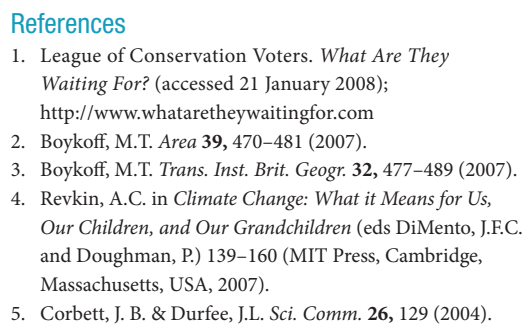

Maxwell T. Boykoff is a James Martin 21st Century Research Fellow at the Environmental Change Institute, University of Oxford. e-mail:maxwell.boykoff@eci.ox.ac.uk 